\title{
Non-Drug Therapy to Combat Coronavirus
}

\author{
Shouguo Wang*, Wei Liu, Yahui Song, Tao Xia, Xianqin Lu, Li Song, Qingwei Li, Jian Sun, \\ Xuemiao Yin, Xianqi Feng, Yunjun Yang, Tao Sun
}

Institute of Frontier Interdisciplinary Studies, Qilu University of Technology, Jinan, China

Email: *wangshouguo@aoe.ac.cn

How to cite this paper: Wang, S.G., Liu, W., Song, Y.H., Xia, T., Lu, X.Q., Song, L., Li, Q.W., Sun, J., Yin, X.M., Feng, X.Q., Yang, Y.J. and Sun, T. (2020) Non-Drug Therapy to Combat Coronavirus. Open Journal of Regenerative Medicine, 9, 65-70. https://doi.org/10.4236/ojrm.2020.92007

Received: April 3, 2020

Accepted: April 27, 2020

Published: April 30, 2020

Copyright $\odot 2020$ by author(s) and Scientific Research Publishing Inc. This work is licensed under the Creative Commons Attribution International License (CC BY 4.0).

http://creativecommons.org/licenses/by/4.0/

\begin{abstract}
Novel coronavirus is threatening the health of people all over the world and all possible treatment strategies are in urgent. The sensitive of virus to heat proposed temperature treatment as an effective method against coronavirus. Here, we proposed several non-drug therapies including far-infrared, thermal air, thermal oxygen, ozone, hydrogen therapy and plasma physical therapy for immediate clinical trial and implementation. Compared with the drug therapy, these methods are safe without side effects, the highest benefit-to-risk ratio, user-friendly, and low implementation costs. It is urgent and significant to start these non-drug therapeutic design and implementation as early as possible, to determine the safety and effectiveness of these therapeutic methods.
\end{abstract}

\section{Keywords}

Non-Drug Therapy, Plasma Physical Therapy, Coronavirus

\section{Introduction}

As of 6:30 on April 20, Beijing time, the novel coronavirus pneumonia cases were diagnosed in 2 million 390 thousand cases, totaling 2,394,291 cases, and the cumulative death rate was more than 160 thousand cases, 164,938 cases in total, according to the statistics of Johns Hopkins University.

Up to now, novel coronavirus pneumonia has not yet been found to be a specific therapeutic drug. However, it is reported that the new coronavirus is very sensitive to heat, and it can be inactivated at $56^{\circ} \mathrm{C}$ for 30 minutes [1]. New coronaviruses have a preference for cold environments. The lower temperature, the longer the survival time, and they can even survive for several years [2] at a temperature of minus $60^{\circ} \mathrm{C}$. In addition, the new coronavirus was also reported to prefer humid and enclosed environments.

Although the virus is sensitive to temperature, we have not seen the use of thermal methods against coronavirus, until today. Tests have proved that, when 
the temperature of the human body is $37.5^{\circ} \mathrm{C}$, the visceral vitality was enhanced by $5-6$ times [3]. With the body temperature of $37^{\circ} \mathrm{C}$, the blood circulation is good, while the basic metabolism is reduced by $12 \%$ at $36.5^{\circ} \mathrm{C}$ and the immune function is reduced by $37 \%$ at $36^{\circ} \mathrm{C}$. So, we have to find a way to improve the body's immunity by increasing the body's temperature. Here, we exemplify these thermal related treatment methods including: far infrared heating, inhalation of thermal air, alternative oxygen and hydrogen therapy, mixture of ozone and air, physical plasma treatment, etc.

\section{Treatment Plan Options}

\subsection{Treatment Plan with New Ventilator}

The novel ventilator of this solution is to kill the virus by increasing the temperature of the inhaled gas and mixing some micro-ozone. In general, the temperature of people's inhaled air depends on the ambient temperature, usually $20^{\circ} \mathrm{C}$. The temperature of exhaled gas is about $36^{\circ} \mathrm{C}$, almost the same as that of health human body. Normally, the resting adult respiratory cycle time is about 6.4 seconds, and the average breath volume is about $500 \mathrm{ml}$ per breath. Calculated according to thermal formula $\left(Q=c m\left(T_{2}-T_{1}\right)\right.$, where $c$ is the air specific heat capacity, $m$ is the air mass, $T$ is the air temperature), supposing the temperature difference between the inhaled and exhaled air is calculated as $16^{\circ} \mathrm{C}$, the breathing energy loss of the human body is about 1386 calorie/h.

If we can breathe $36 \sim 37$ degrees of air, almost the same as body's temperature, which means that we will greatly reduce the burden of heat exchange of respiratory organs and save energy consumption of the body. The new ventilator's design concept is to add a gas relatively thermostatic heater $\left(36^{\circ} \mathrm{C} \sim 37^{\circ} \mathrm{C}\right)$, a pulse gas heater and a pulse micro-ozoner in the breathing tube of the ordinary ventilator, as shown in Figure 1. This new type of ventilator [4] will supply the thermostatic $\left(36^{\circ} \mathrm{C}-37^{\circ} \mathrm{C}\right)$ oxygen and air, the pulse heated oxygen and air, as

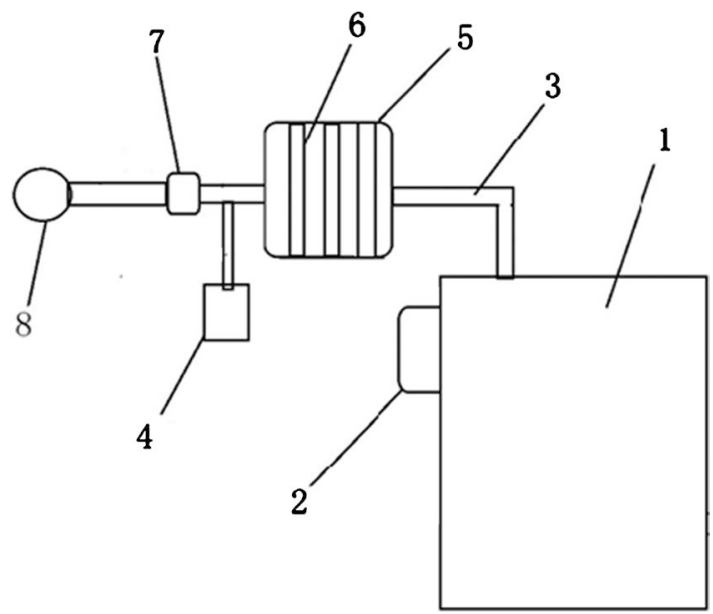

(1. Traditional ventilator 2. Control panel 3. Gas tube 4. Pulse ozone generator 5. Gas thermostatic heater 6. Heating wire 7. Pulse heater 8. Breathing mask).

Figure 1. The diagram of New ventilator. 
well as the pulse micro-ozone. The breathing energy heating loss can be saved with using the thermostatic heater. By using the pulse heater, the temperature of the pulse inhaled gases can be instantly raised to $60^{\circ} \mathrm{C}-80^{\circ} \mathrm{C}$, such pulse thermal gases entering the lung can kill the virus quickly. Furthermore, the pulsed micro-ozone added by the bypass should have a better therapeutic effect of killing coronavirus in the lungs. Why do we use pulse mode, because it is safer and more comfortable for human body.

\subsection{New Treatment Cabin Plan}

The non-drug comprehensive treatment methods are composed of far-infrared heating therapy, oxygen therapy [5], hydrogen therapy [6], and ozone therapy. These treatment units form a complex treatment cabin [7] system, as shown in Figure 2. The treatment cabin has a chamber that contains a temperature-controllable far-infrared heater, an air inlets, an exhausts port, a bluetooth microphone, and the human body monitoring sensors, etc. This chamber is set at a sauna-like temperature of $50^{\circ} \mathrm{C} \sim 70^{\circ} \mathrm{C}$. Such temperature is the typical temperature of sauna-room, so this kind of temperature gas is safe for human body, but, it is deadly for the virus.

With this treatment chamber, the patient can be in a sitting position or on-the-fly therapy. Different comprehensive treatment methods can be adopted according to the patient's symptoms. For example, when the far-infrared thermotherapy is being used, oxygen, air and micro ozone can also be introduced into the thermal cabin chamber. In addition, hydrogen therapy can be used alternately to achieve better therapeutic effect on killing virus probably.

Why does this cabin chamber have therapeutic effect? This is based on the previous trial judgment. Experiments have proved that the far infrared heater can effectively enhance the body's temperature, cure the flu and expel the virus by sweating [8]. The thermal effect of far infrared can promote the speed of blood flow, which means that the white cells in the blood will move more quickly to detect and kill the virus. In addition, elevated body temperature will accelerate the

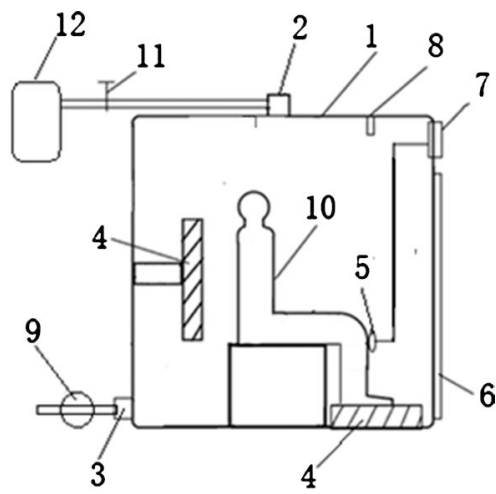

(1. Treatment chamber 2. Inflatable opening 3. Exhaust vent 4. Far infrared heater 5. Sensor 6. Glass door 7. Control panel 8. Bluetooth microphone 9. Air purifier 10. Patient 11. Gas flow control valve 12. Multi-gas tank).

Figure 2. The new treatment cabin. 
microcirculation and basal metabolism [9], enhance immunity [10] [11].

\subsection{Cold Plasma Physical Treatment Plan}

Low temperature cold plasmas have been widely used to sterilize and kill viruses and germs [12] [13] [14], treating diseases caused by various infections [15] [16] [17], because it contains a huge number of energetic particles including electrons, ions, free radicals, ozone, etc.. Based on the previous researches and a single dielectric barrier electrode plasma generator [18], we have designed a nostril plasma sterilizer [19] which can be easily inserted into the nostril, as shown in Figure 3. A micro-discharge plasma can be produced in the casing gap on the side of the ground electrode wall of the shell, as shown in Figure 3 (right). Such a plasma is an air micro-discharge that can produce micro-ozone in the nostril, and its intensity can be modified by controlling a small power supply driven by rechargeable battery. It can be easily attached to clothes. Especially, this plasma sterilizer is safe for the human body with a very small power supply of less than 1 watt.

By easily wearing such a nostril sterilizer, the patient with mild symptoms may inhale some micro-ozone regularly and quantitatively each day to kill the viruses in the nasal cavity, respiratory tract, and lungs. For normal person, you also can reuse and ware it to replace the mask in high-risk infection room with dense crowds.

\section{Conclusions}

Three kinds of non-drug treatment plans are proposed in this paper, including: 1) A new ventilator, which adopts the following improvements: a. Heating the temperature of the inhaled gas to the body's temperature to reduce the burden of pulmonary thermal exchange and save the body energy consumption; b. Using a pulse inhaled gas to kill the virus, c. Using the inhaled micro-ozone to kill the virus. 2) A treatment chamber, which combines the far-infrared thermotherapy, thermal oxygen therapy, thermal air therapy and thermal micro-ozone to improve

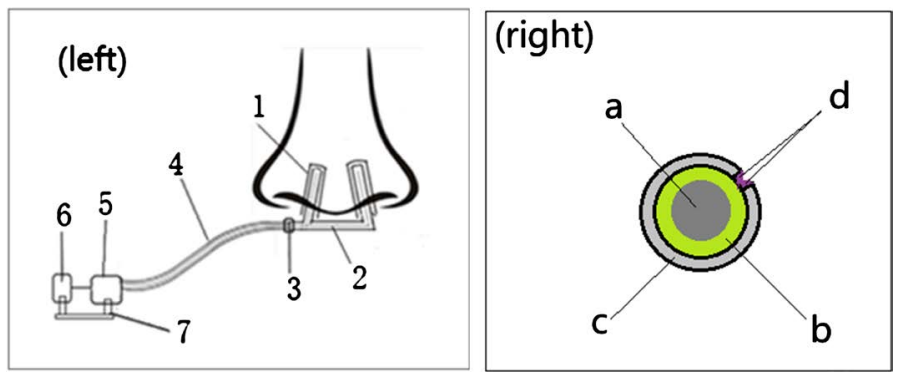

Figure 3. The nostril plasma generator (left) and the small discharge tube (right). Left: 1 . Dielectric barrier discharge tube 2. Connecting rod 3. Connection plug 4. Insulated lead 5. High-voltage pulse power supply 6. Battery 7. Clothes link clip. Right: The detailed cross section structure of the discharge plasma tube 1 including: a. High voltage pulse electrode, b. Dielectric barrier tube, c. Metal sleeve ground electrode with an opening, d. Air micro-discharge cold plasma. 
the microcirculation, the basic metabolism and the immunity, further to make the body sweat to eliminate the virus. 3) The pulse plasma physical micro-discharge tubes, which can be worn easily, to kill the virus in the nasal cavity and then use the inhaled ozone produced by the plasma to kill the virus.

Although the above treatment methods and instruments are still in the early stage, they provide new plans and means for defeating the world epidemic. We are trying to speed up the improvement of these treatment products and start the clinical verification as soon as possible, so as to help the people suffering from the virus to get rid of the pain as soon as possible.

In this emergency period, especially considering the shortage of medical equipment and supplies all over the world, as a temporary emergency method, the authors recommend that the mild patient uses a sauna room with the temperature from $50^{\circ} \mathrm{C}$ to $70^{\circ} \mathrm{C}$ to fight against the virus.

\section{Acknowledgements}

This work was supported by Guangdong Essen Medical Science and Technology Co., Ltd.

\section{Conflicts of Interest}

The authors declare no conflicts of interest regarding the publication of this paper.

\section{References}

[1] Wu, J.T., Leung, K., Bushman, M., et al. (2020) Estimating Clinical Severity of COVID-19 from the Transmission Dynamics in Wuhan, China. Nature Medicine, 26, 506-510. https://doi.org/10.1038/s41591-020-0822-7

[2] Prussin, A.J., Schwake, D.O., Lin, K., et al. (2018) Survival of the Enveloped Virus Phi6 in Droplets as a Function of Relative Humidity, Absolute Humidity, and Temperature. Applied and Environment Microbiology, 84, 1-18. https://doi.org/10.1128/AEM.00551-18

[3] Shao, L., Pang, N., Yan, P., et al. (2018) Control of Body Temperature and Immune Function in Patients Undergoing Open Surgery for Gastric Cancer. Bosnian Journal of Basic Medical Sciences, 18, 289-296. https://doi.org/10.17305/bjbms.2018.2552

[4] Wang, S.G. Ventilator. Chinese Invention Patent, No. 202010147295.0. (Pending Patent)

[5] Fabiola, A., Francesco, M.I., Mariateresa, C., et al. (2020) Hyperbaric Oxygen Therapy in Fibromyalgia and the Diseases Involving the Central Nervous System. Clinical and Experimental Rheumatology, 38, 94-98.

[6] Wu, Y., Yuan, M., Song, J.B., et al. (2019) Hydrogen Gas from Inflammation Treatment to Cancer Therapy. ACS Nano, 13, 8505-8511. https://doi.org/10.1021/acsnano.9b05124

[7] Wang, S.G. Treatment Cabin and Method of Use. Chinese Invention Patent, No. 202010149180.5. (Pending Patent)

[8] Kominami, K., Noda, K., Takahashi, N., et al. (2020) Cardiovascular Reactions for Whole-Body Thermal Therapy with a Hot Pack and Waon Therapy. International Journal of Hyperthermia, 37, 184-191. 
https://doi.org/10.1080/02656736.2020.1723719

[9] Yu, S., Chiu, J., Yang, S., et al. (2006) Biological Effect of Far-Infrared Therapy on Increasing Skin Microcirculation in Rats. Photodermatology, Photoimmunology \& Photomedicine, 22, 78-86. https://doi.org/10.1111/j.1600-0781.2006.00208.x

[10] Chang, Y. (2018) The Effect of Far Infrared Radiation Therapy on Inflammation Regulation in Lipopolysaccharide-Induced Peritonitis in Mice. SAGE Open Medicine, 6, 1-7. https://doi.org/10.1177/2050312118798941

[11] Kim, S., Park, H.T., Soh, S.H., et al. (2019) Evaluation of the Immunobiological Effects of a Regenerative Far-Infrared Heating System in Pigs. Journal of Veterinary Science, 20, e61. https://doi.org/10.4142/jvs.2019.20.e61

[12] Wu, X.Q., Wang, S.G. and Han, L. (2005) Sterilizing Effect of Atmospheric Pressure Plasma Jet on Microbes. Acta Microbiologica Sinica, 45, 312-314.

[13] Xia, T., Kleinheksel, A., Lee, E.M., et al. (2019) Inactivation of Airborne Viruses Using a Packed Bed Non-Thermal Plasma Reactor. Journal of Physics D: Applied Physics, 52, Article ID: 255201. https://doi.org/10.1088/1361-6463/ab1466

[14] Liao, X., Liu, D., Xiang, Q., et al. (2017) Inactivation Mechanisms of Non-Thermal Plasma on Microbes: A Review. Food Control, 75, 83-91.

https://doi.org/10.1016/j.foodcont.2016.12.021

[15] Reitberger, H., Martines, E., Mohr, A., et al. (2018) Cold Plasma to Treat Therapy-Refractive Corneal Ulcers. Klinische Monatsblatter für Augenheilkunde, 235, 1366-1370. https://doi.org/10.1055/a-0792-1301

[16] Nguyen, L., Lu, P., Boehm, D., et al. (2018) Cold Atmospheric Plasma Is a Viable Solution for Treating Orthopaedic Infection: A Review. Biology Chemistry, 400, 77-86. https://doi.org/10.1515/hsz-2018-0235

[17] Sönnergren, H.H., Strömbeck, L. and Faergemann, J. (2012) Antimicrobial Effects of Plasma-Mediated Bipolar Radiofrequency Ablation on Bacteria and Fungi Relevant for Wound Infection. Acta Dermato Venereologica, 92, 29-33. https://doi.org/10.2340/00015555-1171

[18] Wang, S.G. (2017) Plasma Device with a Replaceable (Plug-In) Discharge Tube. PCT/CN 2015000023, Authorized by Japan, Russia, Australian with No. 6535746, No. 2656333, No. 2015376829.

[19] Wang, S.G. Nostril Plasma Sterilizer. Chinese Invention Patent, No. 2020101855229. (Pending Patent) 